\title{
Characteristics of Heart Failure Patients based on Its Causes in Camelia Hospitalization Room Dr. Soetomo General Hospital Surabaya January - December 2017
}

\author{
Chronica Elsa Retta Lumban Tobing ${ }^{1}$, Budi Baktijasa Dharmadjati ${ }^{2^{\star}}$, Heroe Soebroto ${ }^{3}$
}

${ }^{1}$ Faculty of Medicine, Universitas Airlangga, Surabaya, Indonesia.

${ }^{2}$ Department of Cardiology and Vascular Medicine, Faculty of Medicine, Universitas Airlangga - Dr. Soetomo General Hospital, Surabaya, Indonesia.

${ }^{3}$ Department of Thoracic, Cardiac and Vascular Surgery, Faculty of Medicine, Universitas Airlangga - Dr. Soetomo General Hospital, Surabaya, Indonesia.

\section{A B S T R A C T}

Introduction: Heart failure is one of cardiovascular diseases which becomes a global health problem, especially in Indonesia. It's a clinical syndrome caused by variety of underlying diseases. Different causes that cause heart failure in patients will certainly lead to different manifestations and outcomes.

Methods: This research was a descriptive study using secondary data taken from the patient's medical records. The number of samples in this study were 197 patients with heart failure in Camelia Hospitalization Room Dr. Soetomo General Hospital Surabaya. Sampling technique was total sampling. The variables were age, sex, stage, symptoms, physical examination, and pharmacological treatment. The data were analyzed descriptively.

Results: Most heart failure causes in this hospital was coronary heart disease (40.6\%). Patients aged 46-65 years old and male patients were more dominant although the difference was not really significant. Male patients were dominant in heart failure due to coronary heart disease and hypertension, meanwhile female patients were dominant in heart valve disease and other causes. Most patients in all causes of heart failure were diagnosed at advanced stage, such as stage III (35.5\%) and stage IV (35.5\%). Main symptom that was found more in the patients was dyspnea $(70.1 \%)$, which could be found in coronary \& heart valve disease. Physical examination results were based on the causes. Most pharmacological treatments that the patients had were Furosemide (88.3\%) and Spironolactone (73.6\%).

Conclusion: Coronary heart disease still becomes the main cause of heart failure. Heart failure was more common in early and late elderly (46-65 years old), with male patients were more dominant. More patients were diagnosed at advanced stage. Symptom that was found more was dyspnea. Physical examination results were various based on its causes. Pharmacological treatments that the patients had gotten were Furosemide, kind of diuretics, and Spironolactone, kind of aldosterone antagonist.

\footnotetext{
*Correspondence: budibaktijasadharmadjati@gmail.com

JUXTA: Jurnal IImiah Mahasiswa Kedokteran Universitas Airlangga p-ISSN: 1907-3623; e-ISSN: 2684-9453
}

DOI: $10.20473 /$ juxta.V11/12020.32-35

Open access under Creative Commons Attribution-ShareAlike 4.0 International License (CC-BY-SA)

\section{ARTICLE INFO}

Article history:

Received 02 December 2019

Received in revised form 10 January 2020

Accepted 27 January 2020

\section{Keywords:}

Heart failure,

Main symptoms,

Physical examination,

Pharmacological therapy. 


\section{Introduction}

Heart failure is a clinical syndrome, one of cardiovascular diseases which still becomes a global health problem. In developed countries like the United States, it is estimated about 5.7 million adults have been diagnosed with heart failure and more than 870,000 cases of heart failure are found in each year. ${ }^{1}$ This clinical syndrome is more common in men than women and occurs more in those who aged more than 65 years old. ${ }^{2}$ In Indonesia, heart failure is also a serious health problem. Based on doctors' diagnosis, there are 530,068 $(0.3 \%)$ people who have heart failure. From this data, East Java becomes the province that held the highest rate of heart failure, which is $54,826(0.19 \%)$ people. $^{3}$

Basically, heart failure is a clinical condition where the heart has structural and functional disorders that cause cardiac dysfunction in ventricular filling (diastolic) or pumping enough blood to meet the body's oxygen needs (systolic). There are seven etiologies that generally underlie heart failure, such as coronary heart disease, hypertension, heart valve disease, cardiomyopathy, arrhythmias, infections of the heart, coronary heart disease (cor pulmonale), congenital heart disease, pericardial disorders and myxoma (heart tumors), where coronary heart disease, hypertension, and heart valve disorders often become the causes of heart failure. ${ }^{4}$

Differences of heart failure underlying causes in the patients will make different demographic, clinical, and outcome manifestations. ${ }^{5}$ Therefore, in addition to diagnosing heart failure, a medical doctor has to pay attention about underlying disease that causes heart failure. This will make the therapy that has been given to the patients can be done holistically and thoroughly.
The aim of this study was to determine the demographic and clinical characteristics of heart failure patients based on its causes in Camelia Hospitalization Room, Dr. Soetomo General Hospital Surabaya in the January - December 2017 period.

\section{Methods}

This research was a descriptive study using secondary data taken from the patient's medical records at Dr. Soetomo General Hospital Surabaya in January December 2017 period. The number of samples in this study were 197 patients of heart failure who were hospitalized in Camelia Hospitalization Room Dr. Soetomo General Hospital Surabaya, adult patients aged more than 18 years old with Decompensation Cordis or Hypertensive Heart Failure, and had a complete medical record. Sampling technique was total sampling (nonrandom/consecutive sampling). The variables were age, sex, stage (based on NYHA staging), ${ }^{6}$ symptoms, physical examination, and pharmacological treatment (based on recommendation from Indonesian Cardiologist). ${ }^{7}$ The data that had been collected were analyzed descriptively. First, the data were grouped according to their variables and the cause of heart failure. It was focused on Coronary Heart Disease, Hypertension, and Heart Valve Disease. Meanwhile, other causes were grouped in Others category. Then, these data were presented in frequency-distribution tables. This research had received approval of ethical clearance from ethics commission of Faculty of Medicine Universitas Airlangga and Dr. Soetomo General Hospital.

\section{Results}

Table 1. Heart failure patient's profile in Camelia Hospitalization Room Dr. Soetomo General Hospital January - December 2017.

$\begin{array}{lllll}\begin{array}{l}\text { Total } \\ (n=197)\end{array} & \begin{array}{l}\text { Coronary } \\ \text { Heart }\end{array} & \begin{array}{l}\text { Hypertension } \\ (n=29,14.7 \%)\end{array} & \begin{array}{l}\text { Heart Valve } \\ \text { Disease } \\ (n=67,34 \%)\end{array} & \begin{array}{l}\text { Others } \\ (n=21,10.7 \%)\end{array} \\ & \begin{array}{l} \\ (n=80,\end{array} & & & \\ & 40.6 \%) & & & \\ & & & \end{array}$

\begin{tabular}{|c|c|c|c|c|c|}
\hline \multicolumn{6}{|l|}{ Age } \\
\hline$<46$ & $48(24.3 \%)$ & $9(11.3 \%)$ & $3(10.3 \%)$ & $31(46.3 \%)$ & $5(23.8 \%)$ \\
\hline $46-65$ & $116(58.9 \%)$ & $52(65 \%)$ & $19(65.5 \%)$ & $33(49.3 \%)$ & $12(57.2 \%)$ \\
\hline$>65$ & $33(16.8 \%)$ & $19(23.7 \%)$ & $7(24.2 \%)$ & $3(4.4 \%)$ & $4(19 \%)$ \\
\hline \multicolumn{6}{|l|}{ Sex } \\
\hline Male & $99(50.2 \%)$ & $56(70 \%)$ & $15(51.8 \%)$ & $22(32.8 \%)$ & $6(28.5 \%)$ \\
\hline Female & $98(49.8 \%)$ & $24(30 \%)$ & $14(48.2 \%)$ & $45(67.2 \%)$ & $15(71.5 \%)$ \\
\hline \multicolumn{6}{|l|}{ Stage } \\
\hline I & 0 & 0 & 0 & 0 & 0 \\
\hline II & $57(29 \%)$ & $20(25 \%)$ & $11(37.9 \%)$ & $20(29.8 \%)$ & $6(28.5 \%)$ \\
\hline III & $70(35.5 \%)$ & $25(31.2 \%)$ & $15(51.7 \%)$ & $22(32.8 \%)$ & $8(38 \%)$ \\
\hline IV & $70(35.5 \%)$ & $35(43.7 \%)$ & $3(10.3 \%)$ & $25(37.3 \%)$ & $7(33.3 \%)$ \\
\hline \multicolumn{6}{|l|}{ Main Symptoms } \\
\hline Dyspnea & $138(70.1 \%)$ & $52(65 \%)$ & $20(68.9 \%)$ & $52(77.6 \%)$ & $14(66 \%)$ \\
\hline Chest pain & $24(12 \%)$ & $17(21.2 \%)$ & $3(10.3 \%)$ & $1(1.4 \%)$ & $3(14.2 \%)$ \\
\hline Palpitating & $12(6 \%)$ & $4(5 \%)$ & $2(6.8 \%)$ & $6(8.9 \%)$ & 0 \\
\hline Abdominal pain & $2(1 \%)$ & 0 & 0 & $1(1.4 \%)$ & $1(4.7 \%)$ \\
\hline Extremity pain & $5(2.5 \%)$ & $2(2.5 \%)$ & $2(6.8 \%)$ & $1(1.4 \%)$ & 0 \\
\hline Weakness & $3(1.5 \%)$ & $1(1.25 \%)$ & 0 & $2(2.9 \%)$ & 0 \\
\hline Others & $13(6.5 \%)$ & $4(5 \%)$ & $2(6.8 \%)$ & $4(5.9 \%)$ & $3(14.2 \%)$ \\
\hline \multicolumn{6}{|c|}{ Physical Examination } \\
\hline Dyspnea & $66(33.5 \%)$ & $29(36.3 \%)$ & $8(27.5 \%)$ & $25(37.3 \%)$ & $4(19 \%)$ \\
\hline JVP increasement & $39(19.7 \%)$ & $14(17.5 \%)$ & $7(24.1 \%)$ & $17(25.3 \%)$ & $1(4.7 \%)$ \\
\hline Lung rhonchi & $101(51.2 \%)$ & $50(62.5 \%)$ & $15(51.7 \%)$ & $29(43.2 \%)$ & $7(33.3 \%)$ \\
\hline
\end{tabular}




\begin{tabular}{llllll}
\hline Heart murmur & $81(41.1 \%)$ & $9(11.25 \%)$ & 0 & $63(94 \%)$ & $9(42.8 \%)$ \\
\hline Abdominal Distension & $22(11.1 \%)$ & $7(8.75 \%)$ & $2(6.8 \%)$ & $13(19.4 \%)$ & 0 \\
\hline Leg edema & $56(28.4 \%)$ & $24(30 \%)$ & $5(17.2 \%)$ & $24(35.8 \%)$ & $3(14.2 \%)$ \\
\hline & & & & & \\
Pharmacological & & & & & \\
Treatment & & & & & \\
\hline Furosemide & $174(88.3 \%)$ & $73(91.2 \%)$ & $22(75.8 \%)$ & $62(92.5 \%)$ & $17(80.9 \%)$ \\
\hline Spironolactone & $145(73.6 \%)$ & $50(62.5 \%)$ & $20(68.9 \%)$ & $60(89.5 \%)$ & $15(71.4 \%)$ \\
\hline Captopril & $17(8.63 \%)$ & $4(5 \%)$ & $5(17.2 \%)$ & $7(10.6 \%)$ & $1(4.7 \%)$ \\
\hline Lisinopril & $43(21.82 \%)$ & $32(40 \%)$ & $4(13.8 \%)$ & $5(7.5 \%)$ & $2(9.5 \%)$ \\
\hline Ramipril & $55(27.92 \%)$ & $24(30 \%)$ & $3(10.3 \%)$ & $24(88.8 \%)$ & $4(19 \%)$ \\
\hline Valsartan & $14(7.1 \%)$ & $5(6.3 \%)$ & $7(24.1 \%)$ & $1(1.5 \%)$ & $1(4.7 \%)$ \\
\hline Digoxin & $73(37 \%)$ & $32(40 \%)$ & $4(13.8 \%)$ & $30(44.7 \%)$ & $7(33.3 \%)$ \\
\hline Bisoprolol & $50(25.3 \%)$ & $23(28.7 \%)$ & $4(13.8 \%)$ & $14(20.8 \%)$ & $9(42.8 \%)$ \\
\hline
\end{tabular}

The majority of heart failure causes in this hospital was coronary heart disease $(40.6 \%)$. In all causes of heart failure, most patients were $46-65$ years old $(58.9 \%)$. Male patients $(50.2 \%)$ were more dominant than female patients $(49.8 \%)$, although the difference was not really significant. The male patients were dominant in cause of coronary heart disease $(70 \%)$ and hypertension $(51.8 \%)$, meanwhile female patients were dominant in cause of heart valve disease $(67.2 \%)$ and other causes $(71.5 \%)$.

Most patients in all causes of heart failure were diagnosed at advanced stage, such as stage III (35.5\%) and stage IV $(35.5 \%)$. Both stage III and stage IV could be found in heart failure patients because of coronary heart disease $(31.2 \%$ and $43.7 \%)$.

Most main symptoms that can be found in patients were dyspnea $(70.1 \%)$, which could be found each in coronary $(65 \%)$ and heart valve disease $(77.6 \%)$, followed by chest pain $(12 \%)$ that was mostly found in cause of coronary heart disease $(21.2 \%)$, and palpitating $(6 \%)$ that was mostly found in cause of heart valve disease $(8.9 \%)$.

Meanwhile, physical examination results were based on heart failure causes. Overall, lung ronchi was often found in all heart failure patients (51.2\%). Dyspnea and lung rhonchi were more common in heart failure patients with coronary heart disease (36.3\%), (62.5\%). JVP increasement, heart murmurs, and abdominal distension were more common in heart failure patients with heart valve disease (25.3\%), $(94 \%),(19.4 \%)$. Meanwhile, the condition of limb edema was equally common in heart failure patients with cause of coronary $(30 \%)$ or heart valve disease $(35.8 \%)$.

The most pharmacological treatments that the patients got were Furosemide (88.3\%) and Spironolactone (73.6\%). Other than these, most patients with cause of coronary heart disease got Lisinopril and Digoxin (40\% each). In heart failure patients with cause of hypertension, most patients got Valsartan (24.1\%). Then, in heart failure patients with cause of heart valve disease, most patients got Digoxin (44.7\%).

\section{Discussion}

From the data that has been collected, it can be found that coronary heart disease is the most causative disease underlying heart failure $(40.6 \%)$. Certain cardiology studies state that in this era, coronary heart diseases also become one of the factors that contribute to the incidence of heart failure. ${ }^{8}$ Patients with heart failure are mostly in the age range of both early and late elderly, 46-65 years old $(58.9 \%)$. This is thought to be due to changes in cardiovascular structure and function that are periodically affected by old age. These changes in cardiovascular structure and function in the elderly cause the decreasement of chronotropic and inotropic responses, increasement of intracardiac pressure when ventricular filling, and increasement of cardiac afterload. As a result, the ability of the heart to respond to stress is impaired, whether the stress is physiological (exercise) or pathological (myocardial ischemia). ${ }^{9}$

Male patients $(50.2 \%)$ are more dominant and are found in coronary heart disease and hypertension. Men tend to have a lifestyle with risk factors for coronary/ischemic heart disease, such as smoking, alcohol consumption, obesity, and other lifestyles that affect the heart, so that patients are more prone to developing coronary/ischemic heart disease which results in heart failure. ${ }^{10}$ Meanwhile, female patients $(49.8 \%)$ are found in heart valve disease and others. So far, there has been no clear link between women with the occurrence of heart valve disorders. ${ }^{11}$

Most patients were diagnosed at stage III and IV (each $35.5 \%$ ), while those for stage I and II were found to be lower ( $0 \%$ and $29 \%$ ). This is thought to be due to the custom of Indonesians who will only come to the hospital when their symptoms have reached a severe stage, such as shortness of breath while doing light activity, not even stopping for rest. In addition, this high stage condition is found in many heart failure patients with coronary heart disease, presumably due to the low rate of coronary heart disease screening in Indonesia.

Most main symptom that occur in the patients was dyspnea $(70.1 \%)$, which could be found in each coronary $(65 \%)$ and heart valve disease $(77.6 \%)$. With decreasement cardiac output in heart failure due to myocardial capacity that is no longer optimal (due to myocardial infarction or ischemia) or increased intraventricular pressure and volume (due to heart valve disorders), at the end of systole there is more blood remain than normal conditions. In the next diastole phase, the remaining blood will increase again with blood entering the left ventricle so that the final diastolic pressure becomes higher. Over time, much blood will appear in the left atrial region which will be followed by an increase in pulmonary venous pressure and pulmonary capillary artery pressure. In a short time, the hydrostatic pressure in the pulmonary capillaries will become so high and there will be a transudation of fluid from the pulmonary capillaries that will make transudation in the bronchial interstitial tissue. If it continues, the movement of alveoli will also be disrupted that the air exchange process will not going well. This will make the patient feels shortness of breath accompanied by rapid pulse. ${ }^{12}$

Physical examination results were based on heart failure causes. Dyspnea and lung ronchi were found more in heart failure patients with coronary heart disease $(36.3 \%), \quad(62.5 \%)$. This is in accordance with pathophysiology as explained in the previous section. Meanwhile, in patients with heart valve disease, there will be heart murmurs and abdominal distension. Disorders of the heart valves that are caused by rheumatic heart disease will cause auscultatory murmur. In addition, high pressure on the heart due to stenosis or regurgitation will cause 
blood backflow from the heart to peripheral vascular, resulting in JVP increasement (25.3\%), abdominal distension (19.4\%), and leg edema (35.8\%). ${ }^{12}$

The majority of pharmacological therapies given were Furosemide (88.3\%) and Spironolactone $(73.6 \%)$. In a case study of heart failure in developed countries, $84 \%$ of patients received Furosemide therapy or what is often called a strong diuretic (loop diuretic). This is in accordance with the mechanism of action of Furosemide, which uses a minimal therapeutic dose for excessing fluid or salt in the body through urine and relieves swelling due to heart failure. ${ }^{13}$ Meanwhile, Spironolactone or aldosterone antagonist prevents the process of cardiac fibrosis and the process of reverse remodeling, i.e. changes in the structure of the left ventricle which widened in response to the increased heart load caused by aldosterone. ${ }^{14}$

In heart failure due to coronary heart disease, Lisinopril was widely used. This is related to the ability of a class of ACE inhibitors that are well known and are used to reduce mortality and morbidity in heart failure patients due to left ventricular dysfunction. In addition, after 12 weeks of drug administration, Lisinopril will increase exercise time \& patient's activity better than Captopril so that it is used more. ${ }^{14}$ Due to hypertension, Valsartan is also widely used. This is thought to be due to intolerance to ACE inhibitor therapy in the majority of heart failure patients with hypertension. In addition, Valsartan which is included in the Angiotensin Receptor Blocker (ARB) regimen is less likely to cause cough side effects. ${ }^{15}$ Meanwhile, due to heart valve disease, Digoxin is also widely used. Based on Heart Failure Treatment Recommendation from Indonesian Cardiologists, the majority of Digoxin is used in patients with heart failure with atrial fibrillation. This is in accordance with the condition of heart failure patients with heart valve disorders in Dr. Soetomo General Hospital, where most heart valve disorders that occur are a result of rheumatic heart disease that also affects patients.

\section{Conclusion}

Coronary heart disease still becomes the main cause of heart failure. Heart failure was more common in early and late elderly (46-65 years old), with male patients more dominant than female patients. More patients were diagnosed at advanced stage (stage III and stage IV), where both were in equal amount. Symptom that was found more was dyspnea, followed by chest pain and palpitating. Physical examination results were various based on its causes, but lung rhonchi was more common. Pharmacological treatment that the patients had gotten was Furosemide, kind of diuretics, and Spironolactone, kind of aldosterone antagonist. Other than that, there was also one pharmacological treatment that used dominantly in each causes, such as Lisinopril in heart failure with coronary heart disease, Valsartan in heart failure with hypertension, and Digoxin in heart failure with heart valve disease.

\section{CONFLICT OF INTEREST}

The author stated there is no conflict of interest in this study.

\section{REFERENCES}

1. Thibodeau D. Heart Failure. Physician Assistant Clinics. 2017; 2: 651-70.

2. Bui AL, Horwich TB and Fonarow GC. Epidemiology and Risk Profile of Heart Failure. Nat Rev Cardiol. 2011; 8: 30-41.

3. Indonesia PDDIKKR. Situasi Kesehatan Jantung. Jakarta: Kementerian Kesehatan Republik Indonesia, 2013.

4. Mcmurray JJ and Stewart S. Epidemiology, Aetiology, and Prognosis of Heart Failure. Heart. 2000; 83: 596-602.

5. Kajimoto K, Minami $\mathrm{Y}$, Sato $\mathrm{N}$ and Kasanuki $\mathrm{H}$. Etiology of Heart Failure and Outcomes in Patients Hospitalized for Acute Decompensated Heart Failure with Preserved or Reduced Ejection Fraction. Am J Cardiol. 2016; 118: 1881-7.

6. The Relationship of LV Ejection Fraction and Nyha Classification in Congestive Heart Failure Patients. Europace. 2005; 7: 88-9.

7. Indonesia PDSK. Pedoman Tata Laksanan Gagal Jantung. Jakarta: Perhimpunan Dokter Spesialis Kardiovaskular Indonesia, 2015.

8. Lala A and Desai AS. The Role of Coronary Artery Disease in Heart Failure. Heart Failure Clinics. 2014; 10: 353-65.

9. Dharmarajan $\mathrm{K}$ and Rich MW. Epidemiology, Pathophysiology, and Prognosis of Heart Failure in Older Adults. Heart Failure Clinics. 2017; 13: 417-26. 10. Syukri AEDP. Profil Penyakit Jantung Koroner di Irina $F$ Jantung RSUP Prof. Dr. R. D. Kandou Manado. Jurnal E-Clinic (Ecl). 2013; 1.

11. Rosano G. Valvular Heart Disease in Heart Failure. 2017. 2017; 10.

12. Lilly L. Pathophysiology of Heart Disease. Philadelphia: Lippincott Williams \& Wilkins, 2011.

13. Trevisan L, Cautela J, Resseguier $\mathrm{N}$, et al. Prevalence and Characteristics of Coronary Artery Disease in Heart Failure with Preserved and MidRange Ejection Fractions: A Systematic Angiography Approach. Archives of Cardiovascular Diseases. 2018; 111: 109-18.

14. Frigerio $M$ and Roubina $E$. Drugs for Left Ventricular Remodeling in Heart Failure. The American Journal of Cardiology. 2005; 96: 10-8.

15. Tambuwun CF, Panda AL and Rampengan $\mathrm{SH}$. Gambaran Pasien Gagal Jantung dengan Penyakit Hipertensi yang Menjalani Rawat Inap di RSUP Prof. Dr. R. D. Kandou Manado Periode September November 2016. Jurnal E-Clinic (ECL). 2016; 4. 